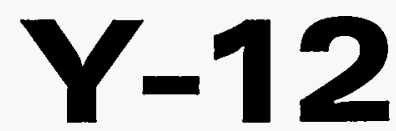

\section{OAK RIDGE $\mathrm{Y}-12$ PLANT}

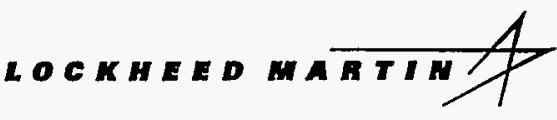

MANAGED BY LOCKHEED MARTIN ENERGY SYSTEMS, INC. FOR THE UNITED STATES DEPARTMENT OF ENERGY
Y/AMT-367

ORNL/M-5066

\section{CRADA Final Report for}

CRADA Number ORNL92-0104

METALLIZATION TECHNOLOGY FOR

TENTH-MICRON RANGE INTEGRATED CIRCUITS

\author{
L. A. Berry
}

S. M. Gorbatkin

Lockheed Martin Energy Systems, Inc. Lockheed Martin Energy Research Corp.

S. M. Rossnagel

J. M. E. Harper

International Business Machines Corporation

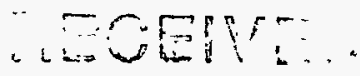

EEC 201996

April 11, 1996

$$
09 \mathrm{~T}
$$

Approved for Public Release;

distribution is unlimited

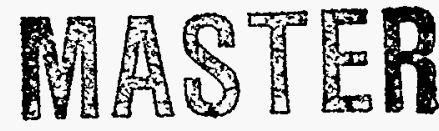

Prepared by the

Oak Ridge Y-12 Plant

Oak Ridge, Tennessee 37831 managed by

Lockheed Martin Energy Systems, Inc.

for the

U.S. DEPARTMENT OF ENERGY

under contract DE-AC05-84OR21400

DISTRIBUTION OF THIS DOCUMENT IS UNLIMITED 


\section{DISCLAIMER}

This report was prepared as an account of work sponsored by an agency of the United States Government. Neither the United States Government nor any agency thereof, nor any of their employees, makes any warranty, express or implied, or assumes any legal liability or responsibility for the accuracy, completeness, or usefulness of any information, apparatus, product, or process disclosed, or represents that its use would not infringe privately owned rights. Reference herein to any specific commercial product, process, or service by trade name, trademark, manufacturer, or otherwise, does not necessarily constitute or imply its endorsement, recommendation, or favoring by the United States Government or any agency thereof. The views and opinions of authors expressed herein do not necessarily state or reflect those of the United States Government or any agency thereof. 


\title{
METALLIZATION TECHNOLOGY FOR TENTH-MICRON RANGE INTEGRATED CIRCUITS
}

\begin{abstract}
A critical step in the fabrication of integrated circuits is the deposition of metal layers which interconnect the various circuit elements that have been formed in earlier process steps. In particular, columns of metal 2-3 times higher than the characteristic dimension of the circuit are needed. At the time of initiation of this CRADA, the state-of-the-art was the production of 11.5 micron-high columns for 0.5 micron-wide features with an expected reduction in size by a factor of two or more within five to ten years. Present commercial technologies cannot deposit such features with the process temperature, aspect ratio (ratio of height to diameter), and/or materials capability needed for future devices. This CRADA had the objective of developing a commercial tool capable of depositing metal (either copper or aluminum) at temperatures below $300^{\circ} \mathrm{C}$ into features with sizes approaching 0.2 micron on $200-\mathrm{mm}$ wafers. The capability of future modification for deposition of alloys of controllable composition was also an important characteristic.

The key technical accomplishments of this CRADA include the development of a system capable of delivering highly ionized metal plasmas, refinement of spectroscopic techniques for in situ monitoring of the ion/neutral ratio, use of these plasmas for filling and lining submicron trenches used for integrated circuit fabrication, and generation of fundamental data on the angular dependent sputtering yield which will prove useful for modeling the time evolution of feature filling and lining.
\end{abstract}




\section{OBJECTIVES OF THE CRADA}

The objective was to develop and demonstrate operation of a system capable of processing integrated circuits with feature sizes approaching 0.2 microns. The system was to be able to fill with metal structures over wafer diameters of $200 \mathrm{~mm}$ with high $(>2)$ aspect ratios. Additionally, a vendor was to be identified for commercialization, and a first commercial prototype was to be developed.

\section{MEETING OF THE OBJECTIVES}

A system capable of producing a highly ionized metal plasma was successfully developed and used to fill features with feature sizes of $0.35 \mu \mathrm{m}$ up to aspect ratios of 3:1. Additionally, during the coarse of the program, a number of key technical issues became apparent and were addressed. For example, the need for a seed layer for submicron high-aspect ratio features emerged, for which the system characteristics must be very different compared to feature filling. The system developed for feature filling was modified and operated to successfully line $0.25 \mu \mathrm{m}, 6: 1$ aspect ratio features. Also, key data for modeling of the feature fill process, namely the angular dependent sputter yield at low energies in a highly ionized plasma environment, was acquired.

Several system improvements were designed and tested to optimize system characteristics for both filling and lining. The largest available wafers from IBM or SEMATECH, 200-mm diameter, were processed.

The specific milestones used to monitor performance are listed in Table 1:

Table 1: Milestones

Date

1993 March

1993 September Yes

1994 April Yes

1994 November No

1995 March Yes

1996 January

1996 March
Status

Yes

Description

Design package for first reactor and detailed program plan for Phase 1 of the program (first 14 months). (Joint with contractor lead.)

Performance of Phase 1 reactor including deposition rate, uniformity, and metal resistivity. (Joint.)

Summary of optimized performance of Phase 1 reactor evaluation of scale-test reactor. (Joint)

Definition of Tool vendor. (Joint with contractor lead.)

Summary of Phase II reactor performance. (Joint.)

Evaluation of vendor relationship and status of commercialization prospects. (Participant lead.)

Final report. Summary of production reactor design/performance and commercialization status. (Joint.)

*Since no formal vendor relationship was established, this was folded into the final report. 


\section{DISCLAIMER}

Portions of this document may be illegible in electronic image products. Images are produced from the best available original document. 
All key technical milestones were met. The work performed as part of this CRADA demonstrated the feasibility of high-density plasma use for integrated circuit manufacturing and, as discussed in Section VI, played a role in steering current research and development directions of U.S. industry. Several tool suppliers were identified with direct connection and interest in this general scope of work. However, a commercial relation with a tool supplier was not accomplished due to the existence of competing cross-licensed patents and early competitive work by the respective suppliers. Nevertheless, the overall goal of developing a U.S. capability in this area has been met, as the new research and development directions have led to the development of manufacturing tools for metalization of integrated circuits.

\section{BENEFITS TO DOE AND DEFENSE PROGRAMS}

Plasma processing of materials to deposit thin films, modify the surface with ion implantation, or remove surface layers is a rapidly growing area of materials processing technology that has been identified in a number of studies, including the National Academy Study on Materials that helped catalyze the Presidential initiative on materials research, as a critical national technology. The experience and know-how gained from this project strengthened the DOE position in this important field.

The specific product was a metal deposition process tool which contributes to the Defense Programs and private sector goal of having a technologically and economically strong U.S. semiconductor industry. Attractive applications in Defense Programs areas that need films or protective coating, including display panel and packaging in the microelectronics field, are likely. For all applications, the technology contributed to development of a new approach that replaces an environmentally incompatible process (hard chrome deposition) with an environmentally friendly process that uses little or no hazardous chemicals. Equipment and processes developed make efficient use of metal resources, have the capability to produce materials superior to those produced with existing PVD technologies, and do not generate any undesirable wastes such as the liquid wastes of electroplating.

\section{WORK ACCOMPLISHED}

The technical work accomplished has been written up in forms suitable for publication in refereed scientific literature. The key elements of the technical accomplishments include: the development of a system capable of delivering highly ionized metal plasmas, refinement of spectroscopic techniques for in situ monitoring of the ion/neutral ratio, use of these plasmas for filling and lining submicron trenches used for integrated circuit fabrication, and generation of fundamental data on the angular dependent sputtering yield which will prove useful for modeling the time evolution of feature filling and lining. Full technical descriptions, which comprise the bulk of this final report, are included as Appendices B-F.

\section{INVENTIONS}

No inventions were reported during the course of this CRADA. 


\section{ASSESSMENT OF COMMERCIALIZATION POSSIBILITIES}

At the beginning of this CRADA, the advantages of using highly ionized metal plasma sources for integrated circuit manufacturing were not clear, and semiconductor equipment manufacturers had no definite plans to incorporate production versions of highly ionized metal plasma systems into their future product lines. As a result of both work done at IBM independently of this CRADA and work performed under this IBM-ORNL CRADA, it became increasingly clear that the advantages of the technology, now called ionized physical vapor deposition (I-PVD), would allow increased capabilities for metallization of integrated circuits. The first two years of the CRADA bridged a time gap in which there was relatively little activity in I-PVD at the equipment vendors. The CRADA activity provided a way to continue exploring possible I-PVD configurations and demonstrated enough success to promote more action.

A number of production tool vendors initiated research and development programs and now have concrete plans for production tools. Although there is little chance for direct licensing of the work performed under this CRADA, the strategy suggested by IBM for this CRADA of rapid publication and results sharing has played an important role in encouraging rapid development of the technology and has helped put U.S. manufacturers in an excellent position to take the lead in production of the next generation of I-PVD based metallization tools. It should be noted that even IBM, which played a pivotal role in educating production tool vendors on the advantages of I-PVD and which performed parallel work outside the scope of the CRADA contract on the I-PVD system closest to the configuration to be used by semiconductor manufacturers, may reap minimal gains from direct licensing.

Companies which have definite product plans for an I-PVD tool include Applied Materials, Varian, and CVC. In fact, I-PVD was identified by Applied Materials as their only viable option for critical dimensions (down to 0.1 micron), for high-aspect ratio plug fill (7:1), for low temperature, and for metallization materials (TiN, $\mathrm{AlCu}$ ). They now have working tools for their Endura-class systems and plan to start shipping beta-site tools in August 1996. Applied has already performed test runs for other integrated circuit manufacturers and is going full-steam towards I-PVD as their primary technology for about 2-3 years out. I-PVD is also being actively considered by several equipment manufacturers for feature lining.

Thus, the work of IBM and ORNL, including work performed at part of this CRADA, has played an important role in the decision of the semiconductor industry to change its course and move towards the use of I-PVD. In addition, innovations used as part of the system design have been refined and made more attractive to industry for use in research systems. For example, our use of a permanent magnet electron cyclotron resonance (ECR) source (originally patented by Tom Mantei) and communications with Plasmaquest influenced the decision of Plasmaquest to develop and sell an ECR research system with a permanent magnet design.

The I-PVD system developed as part of this CRADA shows promise for a variety of other applications for which sputtering has been previously used, such as synthesis of tribological coatings. Boron suboxide coatings, which were developed at ORNL and show promise for tribological applications, are well suited for scaleup using the technology developed as part of this CRADA. Another possible commercial application is the development of a replacement for hard chrome.

\section{PLANS FOR FUTURE COLLABORATION}

Future collaborations are planned for continuing advancement of equipment and process design for integrated circuit metallization. In the near term, data generated during this CRADA on the angular dependent sputter yield at low energies, which up to now has not been available, will be used by IBM and incorporated into modeling of the time evolution of structures during metallization from fluxes containing both neutral and ion components. Collaborations are also 
planned with SEMATECH involving use of techniques developed during this CRADA to produce seed layers for subsequent metallization using electroplating.

Another potential direction for collaboration with both IBM and SEMATECH is to consider higher purity deposition, both from the source side and from the vacuum side. Recent studies have demonstrated that flow of solid thin layers is possible with certain barrier layers under conditions of ultrahigh purity. This suggests that the approach to filling submicron features investigated in this CRADA may still be viable for fills and not just for liners/seed layers for the most aggresive features (i.e., those with dimensions approaching $0.1 \mu \mathrm{m}$ and aspect ratios greater than 3:1).

\section{. VIII. CONCLUSIONS}

During this CRADA, a system was successfully developed capable of producing metal plasmas with ionization fractions between $10 \%$ and $70 \%$. Although more work is needed to fill features needed for the next generation ultralarge scale integration components, 0.25 micron width, 6:1 aspect ratio features were successfully lined. Fundamental data on the angular dependent sputter yield at low energies in an environment suitable for plasma processing was generated and will serve as a fundamental base for modeling of structure evolution during both filling and lining using ionized copper deposition systems.

Although the specific goal of attracting a tool vendor for a joint project was not met, our initial vision of this technology being important for the future was realized. Key companies have put considerable available resources on the problem to work independently while incorporating as much as possible of the information generated as part of this CRADA which was made available to the public. The result is that U.S. semiconductor equipment manufacturers have concrete plans for manufacturing systems and are in a position to take the lead in the production of the next generation of I-PVD based metallization tools. 
Appendix A

PUBLICATIONS AND PRESENTATIONS 
Appendix A

PUBLICATIONS AND PRESENTATIONS

\section{Publications}

S. M. Rossnagel, "Ionized Magnetron Sputtering" Semiconductor International p. 99-102 (February 1996).

L. A. Berry and S. M. Gorbatkin, "Permanent Magnet Electron Cyclotron Resonance Plasma Source with Remote Window," J. Vac. Sci. and Technol. A 13, 343 (1995).

S. Hamaguchi and S.M. Rossnagel, "Simulations of Trench-Filling Profiles Under Ionized Magnetron Sputter Metal Deposition," J. Vac. Sci. Technol. B 13, 183 (1995).

S. Hamaguchi and S.M. Rossnagel, "Surface-Topography Simulations of Ionized Sputter Metal Deposition," in Modeling and Simulation of Thin-Film Processing, ed by C. A. Volkert, R. J. Lee, D. J. Srolovitz, and M. J. Fluss, Materials Research Society, Vol. 389, (1995).

L. A. Berry, S. M. Gorbatkin, and R. L. Rhoades, "Cu Deposition Using a Permanent Magnet Electron Cyclotron Resonance Microwave Plasma Source," Thin Solid Films 253, 382 (1994).

S. M. Rossnagel, "Filling Dual Damascene Interconnect Structures with $\mathrm{AlCu}$ and $\mathrm{Cu}$ Using Ionized Magnetron Deposition," J. Vac. Sci. Technol. B 13, 125 (1995).

S. M. Rossnagel, "Directional and Preferential Sputtering-Based PVD," Thin Solid Films 263, 1 (1995). (Invited Critical Review).

S. M. Gorbatkin, D. B. Poker, R. L. Rhoades, F. C. Doughty, L. A. Berry, and S. M. Rossnagel, " $\mathrm{Cu}$ Metallization Using a Permanent Magnet Electron Cyclotron Resonance Microwave Plasma/Sputtering Hybrid System," to be published in J. Vac. Sci. and Technol. B.

S. M. Rossnagel, "Directional Sputter Deposition for Semiconductor Applications," in BeamSolid Interactions for Materials Synthesis and Characterization, ed. by D. E. Luzzi, T. F. Heinz, M. Iwaki, and D. C. Jacobson, Materials Research Society, Vol. 354, (1995).

S. M. Rossnagel, "Directional and Ionized Sputter Deposition for Microelectronic Applications," Proc. ISSP'95, p. 253, June 8-9, 1995, Tokyo, Japan.

R. L. Rhoades and S. M. Gorbatkin, "Characterization of $\mathrm{Ar} / \mathrm{Cu}$ Electron Cyclotron Resonance Plasmas Using Optical Emission Spectroscopy," submitted to J. Appl. Phys.

S. M. Rossnagel, "Ionized Magnetron Sputtering (I-PVD) for Lining and Filling Trenches and Vias at Room Temperature," Proc. VMIC, p. 576, June 28-29, 1995, Santa Clara, CA.

C. Doughty, S. M. Gorbatkin, and L. A. Berry, "Spatial Distribution of Cu Sputter Ejected by Low Energy Ion Bombardment and Resputtering of Surface Features During Damascene Processing." 
Presentations

S. Hamaguchi and S. Rossnagel, "Conformal Liner Deposition Using Ionized Magnetron PVD Deposition Processes," AVS National Symposium, Minneapolis, Minnesota, October 18, 1995.

C. Doughty, S. M. Gorbatkin, D. B. Poker, R. L. Rhoades, L. A. Berry, and S. M. Rossnagel, "Liner Formation and Feature Filling in a $\mathrm{Cu}$ Permanent Magnet Electron Cyclotron Resonance (ECR) Plasma Deposition," American Vacuum Society National Symposium, Minneapolis, Minnesota, October 18, 1995.

S. M. Rossnagel, "Ionized Magnetron Sputtering (I-PVD) for Lining and Filling Trenches and Vias," VMIC conference, San Jose, California, June 1995.

S. Hamaguchi and S. M. Rossnagel, "Surface Topography Simulations of Ionized Sputtering Metal Deposition," MRS Spring conference, San Francisco, California, April 1995.

S. M. Gorbatkin, R. L. Rhoades, and L: A. Berry, "Permanent Magnet ECR for Cu Metallization," American Vacuum Society $41^{\text {st }}$ National Symposium, Denver, Colorado, October 24, 1994.

S. M. Gorbatkin, "ORNL-IBM CRADA Metallization Technology," SEMATECH, Austin, Texas, October 11, 1994.

L. A. Berry, "ECR Microwave Plasma Systems for Cu Metallization," DPP program review, Albuquerque, New Mexico, July 1994.

L. A. Berry, S. M. Gorbatkin, and R.L. Rhoades, "Cu Deposition Using a Permanent Magnet Electron Cyclotron Resonance Microwave Plasma Source," International Conference on Metallurical Coatings, April 1994.

S. M. Gorbatkin, "ORNL-IBM CRADA," SEMATECH/Sandia/ORNL Umbrella CRADA Meeting, Oak Ridge, Tennessee, October 15, 1993.

L. A. Berry, "ECR Microwave Plasma Systems for Cu Metallization," SEMATECH, Austin Metal FTAB (Focus technical advisory board), September 1993.

L. A. Berry and S.M. Gorbatkin, "Permanent Magnet ECR Plasma Source with Remote Window," SRC Workshop on Copper Interconnect Technology, Troy, New York, August 18, 1993.

There were also numerous broader presentations which included information on the ORNL-IBM Metallization CRADA. For example:

S. M. Gorbatkin, G. T. Alley, J. B. Bates, L. A. Berry, S. C. Jacobson, and J. M. Ramsey, "Selected Programs at ORNL Related to Micro-Systems Development," Ford HAR-MEMMS Workshop, Detroit, Michigan, May 17, 1993.

L. A. Berry, "Overview of ORNL Semiconductor Programs" SEMATECH, Austin, Texas, March 1995.

Invited Talks

S. M. Rossnagel, "Ionized PVD for Interconnects," SEMATECH, February 24, 1995, Austin, Texas. 
S. M. Rossnagel, "Ionized Magnetron Sputter Deposition of $\mathrm{AlCu}, \mathrm{Cu}$ and Ti/TiN," presented at Internal Conference on Film Texture, IBM-Somers, February 8, 1995.

S. M. Rossnagel, "Directional and Ionized PVD," as part of an invited panel discussion, MRS Spring Meeting, April 17-21, 1995, San Francisco, California.

S. M. Gorbatkin, "Electron Cyclotron Resonance (ECR) Microwave Plasmas for Conducting Thin-Film Deposition," Spring 1995 Materials Research Society, April 17-21, 1995, San Francisco, California.

S. M. Gorbatkin, "Copper Deposition Using ECR Plasma/Sputtering Hybrid Systems," International Conference on Metallurgical Coatings and Thin Films, April 24-28, 1995, San Diego, California.

S. M. Rossnagel, "Directional PVD," American Vacuum Society, Arizona Chapter, May 16, 1995, Phoenix, Arizona.

S. M, Rossnagel, "Directional and Ionized Magnetron Sputter Deposition for Microelectronics Applications," ${ }^{\text {rd }}$ International Symposium on Sputtering, June 1995, Tokyo, Japan.

S. M. Rossnagel, "Ionized PVD," American Vacuum Society, New England Chapter, June 1995, Boston, Massachusetts.

S. M. Rossnagel, "Ionized and Directional Magnetron Sputtering," at AMD Seminar Series, June 30, 1995, Santa Clara, California.

S. M. Rossnagel, "Magnetron Sputter Deposition for Interconnect Applications," at Advanced Metallization and Interconnect Systems for ULSI Applications, October 3-5, 1995, Portland, Oregon.

S. M. Rossnagel, "Directional and Ionized Sputter Deposition," at the AVS Symposium on Sputtering, October 15, 1995, Minneapolis, Minnesota.

S. M. Rossnagel, "Ionized Sputter Deposition," at AVS Delaware Valley Meeting, November 15, 1995, Philadelphia, Pennsylvania.

In addition, a short presentation of the metallization effort were given by L. A. Berry to Intel (11/95) and discussions held with Plasma Quest, Applied Materials, and Lam Research.

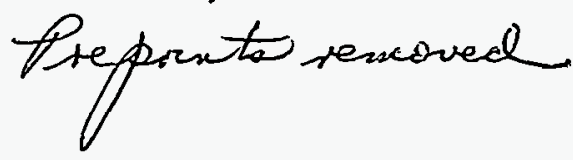




$$
\text { DO NOT SCAN }
$$

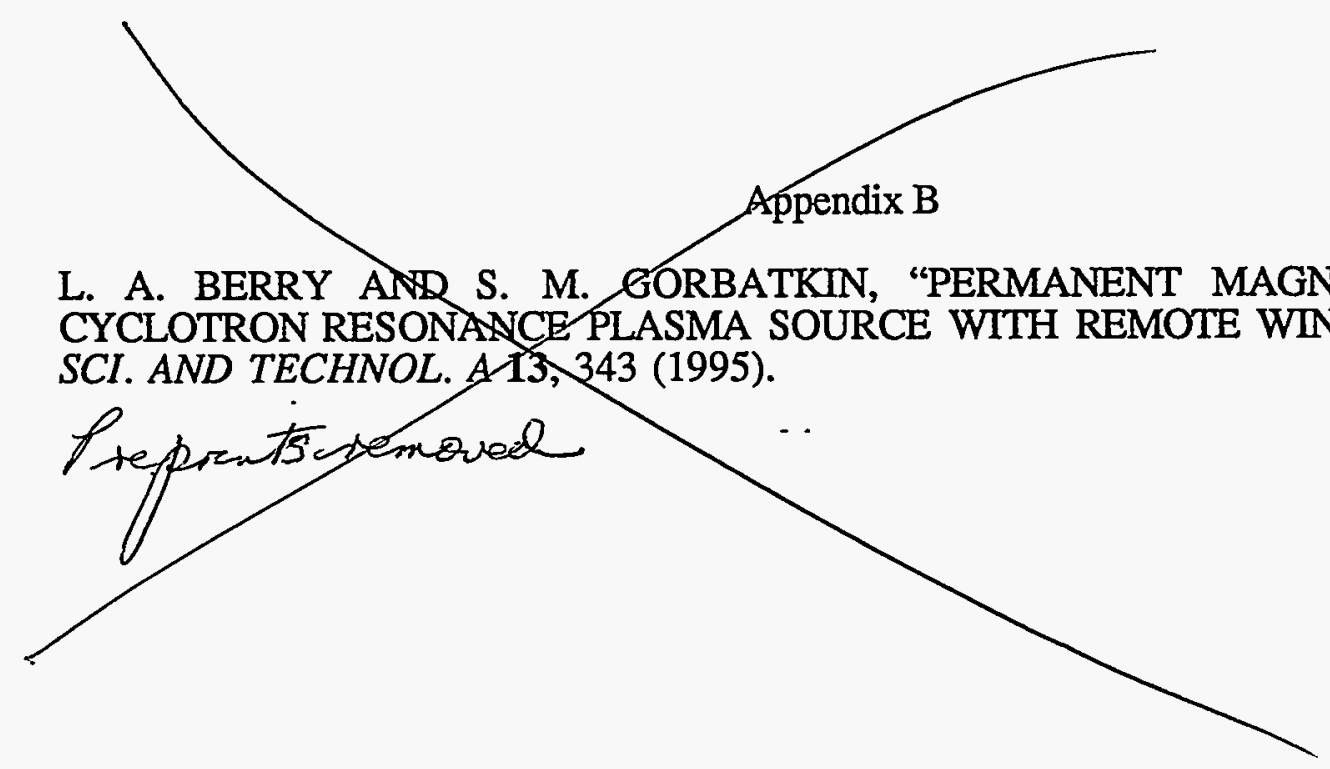


Distribution:

Lockheed Martin Energy Research Corp./Lockheed Martin Energy Systems, Inc./DOE-OR

L. A. Berry, MS-8071, 9201-2 (5 copies)

S. M. Gorbatkin, MS-6057, 3137 (5 copies)

D. B. Poker, MS-6048, 3003

J. B. Roberto, MS-6033, 3025 (5 copies)

D. M. Zehner, MS-6057, 3137

J. E. Ferguson, MS-8242, 701SCA

E. L. Epple, MS-8084, 9203

W. P. Painter, MS-6416, 5002

P. L. Gorman, MS-6269, 4500-N

A. K. Lee/DOE-OSTI, MS-8175, 9983-30 (2 copies)

DOE Office of Patent Counsel, FOB

Laboratory Records, MS-6094, 4500-N

Y-12 Central Files, MS-8169, 9711-5

International Business Machines Corporation

TJ Watson Research Center, PO Box 218, Kitchewan Rd - Rt 134, Yorktown Heights, NY 10598

J. M. E. Harper (3 copies)

S. M. Rossnagel ( 2 copies)

Jurij Paraszczak

M. R. Helgans

Sematech

2706 Montopolis Drive, Austin, TX 78741-6944

Som Bhattacharya

Ken Monnig

Applied Science and Technology, Inc.

35 Cabot Road, Wobum, MA 01801

William Holber 